\title{
Social Changes \& Social Media Usage amongst Emirati Female
}

\author{
Hanan El-Sayed, University of Sharjah, UAE \\ Mohammed Firoz, Australian University Dubai, UAE \\ Suzana Dzamtoska, University of Sharjah, UAE
}

\begin{abstract}
Similar to other world's regions, the reputation and utilization of social media has risen exponentially within few years in the United Arab Emirate (UAE). The upward shift in the UAE female use of social media invited the researcher to conduct this study.

The research aimed at comprehending the reasons behind increase in the social media popularity among the Emirati females. It also investigated the reasons that are causing the Emirati female increase their social media usage. The study, through the methods of comparison with the previous situation in the UAE, methods of analysis and description, is focused on the way of changing traditional believes aligned with females and how women rights in full citizenship was achieved. The study also discusses the social and economic progress in the last decade. It also follows the discussion of Internet stages of development until it reached today's level of usage among the Emirati female.
\end{abstract}

Keywords: Internet accessibility, social media, Emirate females. 


\section{Introduction}

The creation of social media is directed to assist people find each other. In the past, there existed traditional forms of social media such as newspaper, radio and movies, but their influence to people`s lives was small. The discovery of Internet revolutionized every aspect of traditional forms of social media. It changed their delayed passage of message, as most of the traditional media were inaccessible, unresponsive, inflexible, and scheduling (Pejman, 2009). Internet has made social media visible to all willing to use as long as they have Internet access (Eastin and LaRose, 2004). Thus, the social media is no longer a medium of meeting people only, but also became a medium of communication.

In Emirates, the widely used social media includes Facebook, followed by Twitter, while Google lag on third. During Arab Spring, Twitter contributed significantly, as it brought people together (Arabic Knowledge, 2011). Digitally, the Emirates are considered properly connected considering a study undertaken by Telecommunication Regulatory Authority in 2010 , which showed that $99 \%$ of homes in the region had mobile phones, $78 \%$ of the homes could access reliable internet and half of the homestead had a social media account (Strong and Hareb, 2012). Hussein (2013) says Middle East, in the recent years, has emerged a new social media hub. The availability of mobile phones and cheap Internet has enabled the growth of the social media in the region. A survey explored on proportions of social media use showed users of Facebook were 94\%, twitter at 52\% and Google at 46\%. YouTube covered $1 \%$ and other social media such as WhatsApp at 8\%, LinkedIn at 10\%, Instagram at $4 \%$ and others were noted to have strong influence too (Arabic Knowledge, 2011; Physic.org, 2013). YouTube and 'other social media' except LinkedIn occupied a lesser proportion due to their limited commerciality and concentrating a lot on entertainment (Hussein, 2013; Jenaibi, n.d.). LinkedIn has potential of growing in Emirate than Twitter, as it is more commercial than twitter (Hussein, 2013). The users of the social media account prefer the accounts using English other than pure Arabic. Considering the growth of the social media in the region, since 2010, Facebook is estimated to grow at $10 \%$ and Twitter at $20 \%$. Nevertheless, the emerging social media popularity is growing at a higher rate than Facebook or Twitter (Arabic Knowledge, 2011; Dubai School of Government, 2011; Strong and Hareb, 2012).

This research presents a description entailing the background of motives for using social media as based on gratification consequent through studying the reasons for rising in 
popularity among Emirati female. The study also covers various types of social media, information and communication technology elements with background that highlight its features, changes, usage, popularity, significance, and content of changes in relation to Emirati youth in the Arabian Gulf Region.

\section{Methods and Procedures}

The study elaborates the situation in the past in the UAE, with an emphasis on the social changes that have contributed to the growing impact of the Internet and its increased use by women in the UAE. The methods that are used are comparison with the previous situation in the UAE, methods of description and analysis of current situations.

The research analyzed a number of surveys and studies by government and non-governmental organizations. For the research purposes, it was unavoidable to analyze the past, all those changes and positive changes in the social environment in the emirate, which contributed to greater rights for women and that have opened the way for their networking in the global Internet network. The emphasis is on changing traditional believes against women; socioeconomic progress achieved by women in UAE in the past decade - significant changes that have led to social media movement, increased use of the Internet and social networks. As the completion of the research process, there is a comparative overview of the current situation in the UAE and other countries in the Middle East, and the world beyond.

\section{Background}

Fast wealth accumulation from oil mining has made the seven emirates, Abu Dhabi, Umm alQuwain, Ajman, Ras al-Khaimah, Sharjah, Dubai, and Fujairah established in 1971 and ruled by emirs, grow rapidly in terms of communication and economic prosperity (Roben, 2004). According to Dubai School of Government (2012), in the Arab world, there exists ongoing population empowerment by civil movements and political reformists. Social media is highly involved in the ongoing community empowerment (Strong and Hareb, 2012). Since 1970s, Emirates infrastructures have been revolutionized due to influence from institutional affiliations, electronic communication and transnational travel networks (Pinaroc, 2009). Slaughter (2007) states that in the Emirate community, the social media industry has more than 1.7 million followers. Moreover, the social site popularity is exponentially increasing. This has drawn attention from policy makers who are debating over the influence of social 
media at Arab community and the whole world (Mourtada and Salem, 2012). A world Economic Report acknowledges the development in usage of social media in Emirati as it rank the region the leading Arab country in adoption of information and technology (Slaughter, 2007). It also lead in spending huge amount of national income in the adoption of emerging technologies, information and technology hardware and software in social institutions like the hospital, civil projects and schools (Sysomes, 2010). For example, between 2008 and 2011, the government of Emirate region planned to spend \$3.3 Billion (Slaughter, 2007). Emirate government and citizens are striving to remain abreast with rapid changes in technological improvement especially in the usage of internet, as these are effective methods of obtaining information and communicating (Robin, 2004). Actively, most of customers in Emirate utilize online forums to search for product details as many suppliers sell through social media forums (Jenaibi, 2013).

Furthermore, the founder of the Twitter once said the emergence of Twitter was meant to assist individuals keep in touch with each other by quickly looking through a friends list and locate the friend (Strong and Hareb, 2012). According to Urista, Dong, and Day (n.d.), social network common among youths allows them to have own homepage with their own customization in terms of pictures, videos, TV shows, events, movies and much more of their favorites. The social sites allow individuals to have an active responsibility of socializing and developing their own profile in their liking (Strong and Hareb, 2012). As a result, the social media has grown a tomorrow generation that want to remain forever connected through sharing moments and events through online forums (Strong and Hareb, 2012).

\section{Changing Traditional Believes Against Women}

Just like in other Arab world, the Emirate families are considered locus of loyalty, identity, economic prospects, and social status. In Arab settings, their family tends to be large as shown by statistics saying the average number of children to Emirate woman were 6.2 child. Men and women in their families know their roles as assigned by the cultural settings. It is the role of men to provide for the family and ensure its financial status is maintained. Their mode of clothing as influenced by their Muslim customs and hot climates include veils for women and masks called batula to cover their hair and face. In Emirate, women view has changed from the traditional look at women as whom who were illiterate, servants, and followers of wrong religion practices to citizens who enjoy full rights include becoming 
future leaders. According to Abed, Hellyer, and Vine, Sheikh Zayed commented the following at the time of establishment of Emirate: "Nothing could delight me more than to see women taking up their distinctive position in society. Nothing should hinder their progress. Like men, women deserve the right to occupy a high position, according to their capabilities."

True to his words, women in the Emirate have acquired almost equal responsibilities to male. Traditionally, women are never supposed to make appearance in any court leaving their men representative stands on their behalf. The culture used to restrict women from making legal proceeding. The Arab culture recommends any legal claim be solved by consultation and mediation by close friends and family members. Court proceedings were minimized where possible. However, with the changing of ways of life, women prefer to take issues to court and they are demanding to represent themselves there.

This has resulted to changes in regulations and rules to accommodate all citizens in their legal requirements. The legal framework in UAE has evolved to accommodate females more than it was in the year 2005. The Shari Personal Status laws found in the UAE were borrowed from Egyptian and French communal laws. The personal status law regulates matters concerning divorce, marriage, and child custody. UAE most civic laws, consider women as equal as men and their civic testimony consideration have been equated. It is also important to know that most of UAE population is expatriates with their families and only a small portion of the population is considered UAE citizens. Moreover, with the current changes in UAE towards advanced position of women in their society, the government of UAE states it is demonstrating the model of an Arab woman from all aspects of life. Since 2004, the UAE has acceded to reduce discrimination against women through formation legal reforms by giving them equality in matters of nationality, legal capabilities, and equality in family or marriage life through Convection on the Elimination of all Forms of Discrimination against Women (CEDAW). The UAE government has also established rights to child in terms of their nationality, naming right, independence of thought or religion, information access, and adoption.

The UAE nationals are noted as the minority in their own country, but they maintain the positions of great influence, which has enabled them to retain firm ties to their culture, 
particularly enforced to women. It was recently that the government of the Emirate encouraged the Emirate female to contend for 'male job' such as workforce and roles of leadership in the country. Nevertheless, the cultural norms and practices against women never changed especially in their interaction. This restricted their social networks. However, with Internet deployment and large integration into UAE academic and other sectors of life, female will have the opportunity to access bigger social field, which will avail to them the opportunity for self- development and exploration. Thus, the researcher expectation is that Internet play a significant role in forming the ways into which female sculpture their identity exploration.

Furthermore, the change in gender equality in UAE is not automated from the technological innovation. Study of Hedge explains that it was because of intensive restructuring of economic principles, regional integration, and technological advancement to ensure the UAE attained increased dominance in the world as a pioneer display of post-oil growth over its history. When the seven states in Emirate united, after 40 years of failed attempts, structural hindrance developed on how government, society, religious clerks, families, and parent restricted the queer behaviors among the females as national homogeny affected the technology of control. It presented to control bodies, government, society, religious cleric, families and parents, a wide gap between the control of females in their physical environment and cyber space as cyber technology provides a wider space characterized by unfathomable diversity of social power. As an illustration for the above, the Ministry of Social Affairs started a regulatory move, Awareness Initiative, called Mustarjillat, which means that females who throw away female features and try to imitate boys way of living by copying boys mannerism such as clothes acquires female attraction. In the awareness initiative, the Ministry target female youths within educational organizations and youth detention foundations. The non-bureaucratic organizations have also stepped in to try to contain the changes. For example, female students joining Higher College of Technology have to sign an agreement called taahhud, which is an accord that they will behave and uphold sexual conducts. Similarly, female students in all female universities such Zayed University, are constantly observed for display of affection.

In addition, women are copying their male counterpart in business and other risking adventures. According to a study "UAE women entrepreneurs and their businesses", done on 
young females in the UAE, about it was noted that most of women entrepreneurs were in there twenties. Among the women entrepreneur, most of them are well educated as more than $2 / 3$ had a Master's degree. Their degrees were obtained locally as only $20 \%$ of them had gone abroad to further studies, unlike a parallel study investigation on male entrepreneurs in the UAE where more than a half studied from abroad. These women marked networking fuelled their business success.

The consequence of over regulation against gender in the real space, it comes as no surprise that the female Internet users in the UAE acquire a second position in the world ranking in acquiring social site memberships. The queer subjectivity extension into a social site within the UAE is also linked up with government efforts to grow information and communication networks. It has been noted that UAE females have greater interest in joining the world community more than other youth in the Arab world. Thus, the female behavior in the UAE provides an ambitious gap for examining the role played by telecommunication and social sites emergence and the new forms of behaviors in the social sites.

\section{Socio-Economic Progress Achieved by UAE Women in the Past Decade}

Social media usage remains high among the most active users of social media and professional networking sites in UAE (Bandura, 1985). They use Facebook, LinkedIn and Twitter among others. Clearly, this high usage of social media opposes a stereotype of the Arab region as lagging behind with regard to technology and being less connected (David, 2013). The societal and political changes occurring in the Arab region have played a crucial role in challenging stereotypes about Arab females as subjugated and subservient (Daniel, 2013). To begin with, women have played a significant role in coordinating and participating in social uprisings in the Arab world (Tunisia, Egypt and Yemen). This has strongly cemented their roles as equal partners to men in changing the political arenas in their countries (Cohen, 2011; Bill, 2013). This leadership role by women has been acknowledged through the awarding of the Nobel Peace Prize to an Arab woman. Tawakkul Karman is a prominent Yemen political activist. This clearly depicts that social media has played a significant role in women social and economic empowerment (Benat, 2013; Bayt, 2013).

According to a study carried out on "Social Media in the Arab World: the Impact on Youth, Women and Social Change" social media is a crucial instrument for women's empowerment. 
Majority of the participants agreed that social media had the capacity to be an empowering and connecting tool for females in social, economic, as well as legal, political and public arenas (Weinstein, 1980; Watts, 2003). These conceptions, however, differ from the reality of gender disparities that exist in the Arab world as it pertains to these aspects. As a result, social media can possibly be a change instrument with regard to women's empowerment in Arab societies. Majority of participants presented that social media is an enabler of both youth and women empowerment. However, gender disparities exist in real life in many facets of the Arab world. This is clear given the region's low rankings with regard to gender equality inside the political empowerment, as well as economic involvement pillars of various female's empowerment indices (Wafa, 2012; Awad and Ramona, 2012).

The UAE has adopted Information Communication Technology (ICT) as a way of creating a competitive economy and fostering citizen services. However, the affluent Gulf state has put some restrictions on the use of online tools that seem to challenge the government's authority. These restrictions are meant to avert access to local and global voices that vary from the state's viewpoint with regard to politics, religion, as well as gender matters. Similar to other states in the Gulf region, Emirati Internet users take advantage of a robust ICT, as well as high connection speeds. The population that uses the Internet has increased from 61 percent in the year 2007 to 85 percent in the year 2012. In early 2013, there were over 900 , 000 Internet users in the region with 99 percent using broadband connections. However, it is crucial to note that, broadband connection in the UAE is amongst the most expensive in the globe with annual spending of approximately \$2, 178 per account (The Arab World Online, 2013). The UAE also has the highest mobile phone accessibility amongst its populace. The penetration rates accounted for roughly 170 percent in the year 2012. Of all the 26 nations that were involved in the Google Survey on Smart phones, the UAE was ranked the first with 61 percent mobile users who declared they owned personal Smart phones (Van 2013; Alexander, 2011).

According to UNICEF, literacy levels among the Emiratis were approximately 94 percent among men and 97 percent among women. As a consequence, there were no apparent obstacles to Internet usage. This clearly showed a remarkable increase in women empowerment education wise. For further engorgement for computer education the government incorporated computer laboratories in civic schools, thereby attempting to foster 
computer literacy among the young people. The social media in the UAE has tremendously enhanced women economic, social, as well as political empowerment even though a lot of restrictions exist with regard to access of online content. The state exercises state and selfcensorship and has a Cyber-crime law that was adopted in 2012 (Arab Social Media Report, 2011).

\section{Social Media Movement Wave}

Dubai School of Government highlights the occurrence of continuous growth in terms of increased diversity and popularity among the social media adoption in the year 2012 far beyond the heights of the Arab spring. It is a sign of emergence of social media movement wave sweeping through the Emirate region, which is not the only contribution of development in information and technology networks, but incorporation of higher organic growth occurring and establishing connection among Arab communities and societies (Mourtada and Salem, 2012).

In Emirates, the social media usage shifted from social to political and recently, it has evolved to become mother of modification of businesses, social set ups, civil and political. Social media has many Arab users and the number is increasing, which has made the government appreciate the possible influence from the media. Emirate government is seeing this as a chance of innovation and collaboration into more transparent, inclusive, and participatory ways of governing. Many Arab youths are using social media for interaction such as business, social, approach current governance and take on civil movements.

According to Dubai School of Government a survey conducted in 2011 to investigate men and women social activities found out that women engagement in civil activity and governance through social media showed that women in Emirates were $62 \%$ and most of them were between age 15 and 40 years, while $40 \%$ of them held a master's degree. In its analyses, the media found a high gap between genders in population usage of social media in the Emirate. When the participants were asked about the barriers holding them from making full use of the social media, majority of the respondents noted some cultural and societal constraints acting on Arab world women. The study also delved further into the issue of men and women usage of social media by investigating into trends followed by men and women when in social media. It found out that the trends were similar between male and female. 
Male and female utilized the social media to network, obtain vital information like advertisement or job related knowledge and activism ranking. The activism ranking was further followed in the above study and it provided how men and women engaged into activities of their empowerment through social media. Most of the studied sample subjects noted that social media could enhance women's participation in activities boosting political, legal, economic, civil, and social aspects of the society.

Despite the study limiting as the Emirati women who participate in social media covers only $5 \%$ of Emirati community actively engaged in social media, it gives a great hope as the Emirati women have been drawn as the potential future leaders. Emirati government is campaigning to improve women's position as the tomorrow's leaders and improve their assimilation into more and higher ranking employment opportunities. According to UAE report on government website, the UAE government is described as the model to empowerment of Arab women. The effort to bring equality of gender in UAE has also been noted by international forums such as the World Economic Forum when they were analyzing gender index in 2011. The UAE was noted as the top Arab country in upholding of gender equality. Although it ranked below the 100th mark, the Gender Gap Report, the committee applauded the significant input by UAE government in its attempt to educate women. Mostly, it highlighted the important step the UAE government has employed in providing free university education to all Emiratis irrespective of their gender. Accordingly, women have responded positively to this important step, by showing higher numbers of female graduates than male in Emirate universities. Emirati women have also grown politically. For instance, one of the most powerful women in the world as ranked by the Forbes is Qasimi Sheikha, Minister for Economy in the UAE. Similarly, Emirate empowerment of women is visible through UAE Federal National Council as there is significantly higher number of women participants in every year of council's election. When the council was established it included 8 women only, but currently, the number has risen to 85 out of 469 .

Comparing the current development in the UAE with the old lifestyle in this country by 1971 , there has been a huge step of change within a short time. In 1971, the country was characterized by poverty and illiteracy. There was only one newspaper and people traveled long to acquire primary education at high cost. Within just the first several years of the union, the Emirates government has managed to make a whole time change in most ways of future 
generations' style of life. That brave decision was taken after conducting a survey that resulted in the fact that none of the current century females in the country had a mother with computer literacy. The women in the Emirati current generation have managed to develop beyond comprehension of communication technologies and they have developed enormous competence. They are considered heavy Internet users as most of them spend an average of seven hours a week. A study by YouGovSiraj in 2010 found out that more than $71 \%$ of UAE females were active participant in the social media, either to develop their connections, gather information, or to experiment identities.

In order to consider the above communication and information media establishment in the UAE by the government through uses and gratification theory, it is possible to derive what people do to media. From the above, the UAE government has enhanced the cyber communications in a stylish and standard ways just like any other normal human undertaking. As the government of Emirates concentrate on expanding information and technology to its citizens, the society goes through dramatic change.

It has been noted that with the growth of internet usage to connect social media websites, youngsters grow dependent and become addicted to Information and Technology facilities such as mobile phones and computers, as these devices become the chief gadget of connecting, learning, sharing and researching. When the government of UAE provided communication facilities, it was providing computing facilities to assist in scientific discoveries and growing of businesses. However, after their installation, gadget as phone, computer, and Internet connection are "must have" for the Emirate females. Education has improved as education providers have started offering decent technological based knowledge. The youth from high and primary schools are finishing their education with literacy to information and technology beyond imagination.

\section{Nowadays: Women and Social Media around the World and In the UAE}

Social media has played a huge role throughout the popular uprisings through mobilizing activities and sharing of information in the Arab region. However, women's usage of social media is relatively low as compared to those of males in the region and the international female usage average. For instance, females account for roughly half of Facebook users worldwide. However, only a third of these users are in the Arab region. In this region, males 
remain twice likely as females to be users of social media platforms. The obstacles to women's use of social media both around the globe and in the UAE can be attributed to both environmental and individual factors. Environmental factors cover the societal and cultural limitations that women face globally and more so in the Arab region. Individual aspects encompass lack of skills and capacities of the female social media users, lack of ICT literacy, lack of assurance in social media as a channel of communication, as well as limited level of reliance in ICT's safety and privacy. As a consequence, closing this virtual gender gap calls for overcoming the environmental hindrances by tackling discriminatory aspects as well as cultural limitations of women. Majority of males and females in the Arab world fundamentally agree on aspects connected to social media and its impacts on women and civic involvement. They harbor similar ideologies on the function of social media in fostering women's empowerment. Social media usage and penetration is the highest in the UAE compared to countries in the Middle East. UAE has approximately $54 \%$ of its populace on Facebook and this number increases to $78 \%$ of all its Internet users. Comparing the UAE with the US, which has over 150 million Facebook users, the UAE's infiltration rates are higher both with regard to its population and number of Internet users. With this high penetration rates, the UAE is the seventh highest in the globe. In countries like Tunisia, similar to the UAE, approximately 78 percent of its Internet population is on Facebook. Nonetheless, the penetration rates to the entire population are relatively low at 26 percent. Egypt, which has a penetration rate of 11 percent, has 47 percent of its Internet users on social media platforms. Regardless of the low penetration numbers, Egypt harbors the most Facebook users in this region with slightly above 9 million users. Saudi Arabia and Morocco trail behind Egypt with only over 4 million users each. Algeria, Tunisia, Jordan and the UAE harbor 2 million users each while Lebanon and Iraq have roughly over 1 million Facebook users (Arab Social Media Report, 2012).

While throughout the globe, the trend has been that more women use social networks more than men, in the Middle East, this is the total opposite. Fewer women in this region use the social networks accounting for just a one third of all Facebook users in the region. Lebanon depicts the most balanced ration with female users accounting for approximately 44.3 percent of the country's Facebook users. Jordan and Tunisia depict 41.3 percent of female users while Bahrain represents 40 percent. Yemen, Iraq and Mauritania depict a much lower ratio of roughly 20 percent each. However, according to an online study carried out by a research 
firm called Effective Measure, 40 percent of the UAE's online community are females over and above the region's aggregate of 28 percent. In this study UAE has Gulf's biggest number of female Internet users. As a consequence, the Arab state represents a possibly lucrative market for online organizations. It is also presents that the UAE has the second highest women Internet user populace in both the Middle East and North Africa (MENA) region. This is only second to Morocco's 46.6 percent. As a consequence, these numbers provide good prospects for online companies especially those providing consumer goods with the aim of reaching female users. This is because women are highly hunted Internet users online for business since they are fewer and in sites that attract more females, there is increased value. Which had over 68, 000 Internet users from every part of the region, revealed that women Internet users surfed more online from their homes. In addition, 67.3 percent accessed the Internet using home broadband connections. On the other hand, it was crucial to note that, while the UAE had the highest Internet penetrations in the Gulf region, it lagged behind other Arab countries regarding the quality of broadband services. The UAE is in the bottom 25 percent of the Gulf region's states regarding the delivery of broadband services. UAE follows Bahrain, Qatar, and Saudi Arabia among other nations. In this study, broadband quality of service was defined as the speed and responsiveness of Internet connections. This also describes the condition of the connection lines whether congested or unpredictable (Yun and Trumbo, 2000; Zillmann, 1994).

\section{Results and Conclusion}

The use of social media has rapidly increased in the UAE. These social networks include Facebook, YouTube, as well as Twitter among others. The UAE population is very skilled in the use of an assortment of social media. They also understand the proper moral and practical limitations of social media. Social media has served as a crucial source of information, news, sharing of ideas, business development, as well as cultural production and entertainment. Phone, computer, and Internet connection those days became "must have" for the Emirate females. Education has improved as education providers have started offering decent technological based knowledge. The youth from high and primary schools are finishing their education with literacy to information and technology beyond imagination.

With Internet deployment and large integration into UAE academic and other sectors of life, female will have the opportunity to access bigger social field, which will avail to them the 
opportunity for self- development and exploration. Internet play a significant role in forming the ways into which female sculpture their identity exploration. With the current changes in UAE towards advanced position of women in their society, the government of UAE states it is demonstrating the model of an Arab woman from all aspects of life. All the positive changes in the society - traditional believes against women, social and economic progress achieved by UAE Women, resulting in an increasing use of social networks by women. Internet accessibility in Emirate has formed a tool to deliver female from social isolation and traditional pressure. Even more actual trend has been shown that women used the social networks more than men, in the Middle East.

\section{References}

Alexander, K., 2011. What being an Emirati truly means. Gulf News.

Arab Media Outlook, 2012.Collaborating for growth. Forecasts and analysis of traditional \& digital media in the Arab world.

Arab Social Media Report 2013, ASMR in the media, [Online] Viewed $9^{\text {th }}$ May 2014, 〈http://www.arabsocialmediareport.com/home/index.aspx $>$

Arab Social Media Report, 2011.The Role of Social Media in Arab Women's Empowerment. Dubai School of Government.

Arab Social Media Report, 2012.Social Media in the Arab World: Influencing Societal and Cultural Change. Dubai School of Government.

Awad, M., and Ramona, R., 2012. "Cyber-crime law to fight internet abuse and protect privacy in the UAE."

Arabic Knowledge,2011.Preparing Futur Generations for Knowledge Society.Mohammed bin Rashid Al Maktoum Foundation.

Bayt, 2013. The Arab World Online: Trends in Internet Usage in the Arab Region. Dubai School of Government.

Benat, 2013. “The Global Information Technology Report 2013,” World Economic Forum.

Bill, M., 2013. "Hacked Website, Java Vulnerability Used to Target UAE Activist with Spyware,” Bahrain Watch, January 15.

Cohen, H., 2011. 30 Social Media Definitions. An E-book.

David, H. 2013. “The UAE's bizarre, political trial of 94 activists, ” The Guardian. 
Eastin, M., and LaRose, R. 2004. A Social Cognitive Theory of Internet Uses and Gratifications: Toward a New Model of Media Attendance. Journal of Broadcasting and Electronic Media.

Hussein, U S 2013, Social media in the Middle East in 2013, Social Media Chimps, [Online] Viewed $9^{\text {th }}$ May, 2014, < http://socialmediachimps.com/infographics/social-media-inthe-middle-east-2013/>

IAEA,2013http://wwwpub.iaea.org/MTCD/Publications/PDF/CNPP2013_CD/countryprofile s/UnitedArabEmirates/UnitedArabEmirates.htm.[Accessed: 28 November 2013

Jenaibi, B., 2013.Use of Social Media in the United Arab Emirates: An Initial Study. Global Media Journal.

LaRose, \& Eastin, M. (2004). Attachment, social support, and loneliness in young adulthood:

A test of two models. Personality and Social Psychology Bulletin, 28(5), 684-

693.CrossRef,Web of Science® Times Cited: 10

Mourtada, R., and Salem. F., 2012. Social Media in the Arab World: the Impact on Youth, Women and Social Change. Dubai School of Government.

Pejman, P. 2009. Arab Media \& Society, Feature Article, The Middle East Centre St.Antony's College

Pinaroc, 2009.UAE has Gulf's highest female Internet user base.

Roben, Mansell Political economy, power and new media." LES Research online(2004): 7483.

Strong, C. and Hareb, H., 2012. Social Media Fashion among Digitally Fluent Young Arabic Women in the UAE. Journal of Middle East Media.

Sysomos. 2010. Twitter Statistics for 2010: An in-depth Report on Twitter's Growth. Marketwire. Toronto.

Van, D., 2013. The Culture of Connectivity: A Critical History of Social Media. Oxford: Oxford University Press.

Wafa, I., 2012. Muslim Brotherhood invading UAE social media: police chief.

Watts, D., 2003. Six Degrees: The Science of Connected Age: London: Vintage.

Weinstein, N., 1980.Unrealistic optimism about future life events. Journal of Personality and Social Psychology. 